\title{
Beat-to-Beat P-Wave Analysis Outperforms Conventional P-Wave Indices in Identifying Patients with a History of Paroxysmal Atrial Fibrillation during Sinus Rhythm
}

\author{
Dimitrios Tachmatzidis ${ }^{1, *} \mathbb{0}$, Dimitrios Filos ${ }^{2}$, Ioanna Chouvarda ${ }^{2} \mathbb{D}$, Anastasios Tsarouchas ${ }^{1} \mathbb{D}$, \\ Dimitrios Mouselimis ${ }^{1}{ }^{1}$, Constantinos Bakogiannis ${ }^{1}$, Charalampos Lazaridis ${ }^{1}$, Konstantinos Triantafyllou ${ }^{1}{ }^{\mathbb{D}}$, \\ Antonios P. Antoniadis ${ }^{1}$, Nikolaos Fragakis ${ }^{1}$, Georgios Efthimiadis ${ }^{3}$, Nicos Maglaveras ${ }^{2}{ }^{\mathbb{D}}$, \\ Dimitrios G. Tsalikakis ${ }^{4}$ and Vassilios P. Vassilikos ${ }^{1}$
}

1 3rd Cardiology Department, Hippokrateion General Hospital, Aristotle University of Thessaloniki, 54642 Thessaloniki, Greece; tasos.tsarouchas@gmail.com (A.T.); dimitriosmouselimis@gmail.com (D.M.); bakogianniscon@gmail.com (C.B.); charalamposlazaridis86@gmail.com (C.L.); kostrianta@hotmail.com (K.T.); aantoniadis@gmail.com (A.P.A.); nfrag@auth.gr (N.F.); vvassil@med.auth.gr (V.P.V.)

2 Lab of Computing, Medical Informatics and Biomedical Imaging Technologies, School of Medicine, Aristotle University of Thessaloniki, 54124 Thessaloniki, Greece; dimitrisfilos@gmail.com (D.F.); ioanna@med.auth.gr (I.C.); nicmag@auth.gr (N.M.)

3 1st Cardiology Department, AHEPA University Hospital, Aristotle University of Thessaloniki, 54621 Thessaloniki, Greece; geythymi@auth.gr

check for updates

Citation: Tachmatzidis, D.; Filos, D.; Chouvarda, I.; Tsarouchas, A.; Mouselimis, D.; Bakogiannis, C.; Lazaridis, C.; Triantafyllou, K.; Antoniadis, A.P.; Fragakis, N.; et al. Beat-to-Beat P-Wave Analysis Outperforms Conventional P-Wave Indices in Identifying Patients with a History of Paroxysmal Atrial Fibrillation during Sinus Rhythm. Diagnostics 2021, 11, 1694. https:// doi.org/10.3390/diagnostics11091694

Academic Editor: Ernesto Di Cesare

Received: 9 July 2021

Accepted: 15 September 2021

Published: 17 September 2021

Publisher's Note: MDPI stays neutral with regard to jurisdictional claims in published maps and institutional affiliations.

Copyright: (C) 2021 by the authors Licensee MDPI, Basel, Switzerland. This article is an open access article distributed under the terms and conditions of the Creative Commons Attribution (CC BY) license (https:// creativecommons.org/licenses/by/ $4.0 /)$.
4 Department of Informatics and Telecommunications Engineering, University of Western Macedonia, 50100 Kozani, Greece; dtsalikakis@uowm.gr

* Correspondence: tachmatzidis@gmail.com
Abstract: Early identification of patients at risk for paroxysmal atrial fibrillation (PAF) is essential to attain optimal treatment and a favorable prognosis. We compared the performance of a beat-to-beat (B2B) P-wave analysis with that of standard P-wave indices (SPWIs) in identifying patients prone to PAF. To this end, 12-lead ECG and 10 min vectorcardiogram (VCG) recordings were obtained from 33 consecutive, antiarrhythmic therapy naïve patients, with a short history of low burden PAF, and from 56 age- and sex-matched individuals with no AF history. For both groups, SPWIs were calculated, while the VCG recordings were analyzed on a B2B basis, and the P-waves were classified to a primary or secondary morphology. Wavelet transform was used to further analyze P-wave signals of main morphology. Univariate analysis revealed that none of the SPWIs performed acceptably in PAF detection, while five B2B features reached an AUC above 0.7. Moreover, multivariate logistic regression analysis was used to develop two classifiers-one based on B2B analysis derived features and one using only SPWIs. The B2B classifier was found to be superior to SPWIs classifier; B2B AUC: 0.849 (0.754-0.917) vs. SPWIs AUC: 0.721 (0.613-0.813), $p$ value: 0.041 . Therefore, in the studied population, the proposed B2B P-wave analysis outperforms SPWIs in detecting patients with PAF while in sinus rhythm. This can be used in further clinical trials regarding the prognosis of such patients.

Keywords: P-wave indices; beat to beat; P-wave analysis; atrial fibrillation; wavelet analysis; diagnostic model

\section{Introduction}

Atrial fibrillation (AF) — the most common sustained cardiac arrhythmia — while not a life-threatening condition itself, leads to an increased risk of stroke or heart failure and high rates of mortality [1]. Therefore, early detection and diagnosis of AF is a critical issue for all health stakeholders. Identifying individuals at a higher risk of developing AF is feasible using predictive models based on clinical variables, circulating biomarkers, and P-wave indices (PWIs) [2]. 
The P-wave on the resting 12-lead electrocardiogram (ECG) is a representation of atrial depolarization, providing a wealth of information valuable in predicting incident AF. The PR interval and other standard PWIs (SPWIs) such as P-wave duration, P-wave terminal force in lead $\mathrm{V}_{1}\left(\mathrm{PTFV}_{1}\right)$, interatrial block (IAB), P-wave area, and P-wave axis, along with QT interval, ECG-derived ventricular hypertrophy, and incidence of atrial and ventricular ectopy have been proposed as potential identifiers of individuals at risk for developing AF [3]. Similarly, clinical risk scores such as the $\mathrm{CHA}_{2} \mathrm{DS}_{2}$-VASc score have been directly associated with the incidence of new-onset AF [4]. Furthermore, the association of PWIs with conditions beyond AF underlines their clinical importance. Therefore, PTFV $1, \mathrm{P}_{-}$ wave duration, advanced IAB (a-IAB), and P-wave area have been correlated with stroke incidence $[5,6]$. Moreover, the addition of the P-wave axis to the standard $\mathrm{CHA}_{2} \mathrm{DS}_{2}-\mathrm{VASc}$ score improved its performance in stroke prediction [7].

More sophisticated ECG indicators derived from P-wave wavelet analysis have been used in patients with no evidence of structural heart disease or any other predisposing factors to successfully identify those at risk of developing AF [8]. It has also been shown that during sinus rhythm, multiple $\mathrm{P}$-wave morphologies are present more frequently in patients with a history of AF [9], indicating differences in the electrical substrate of the atria [10]. Thus, morphological variability, along with beat-to-beat (B2B) wavelet analysis, is proposed as an integrated approach to P-wave analysis.

The present study aims to compare the performance of B2B P-wave analysis with that of traditional predictors of paroxysmal atrial fibrillation (PAF), such as SPWIs, in identifying patients with a history of PAF during sinus rhythm. The superiority of a B2BP-wave analysis-based classifier over a SPWIs-based one would support the hypothesis that P-wave B2B morphological alterations provide a wealth of information on atrial predisposition to AF that SPWIs cannot reveal.

\section{Materials and Methods}

We invited 40 consecutive patients with newly diagnosed (less than a month) PAF and no history of antiarrhythmic medication to participate in the study; 60 age- and gender-matched individuals without any history of PAF or structural heart disease were used as the control group. Patients with comorbidities, such as previous cardiovascular surgery, previous cardiac ablation, heart failure NYHA class III-IV, severe valvular heart disease, prosthetic valves, reduced life expectancy, age $>75$ years, atrioventricular block, presence of implanted pacemaker or cardiac defibrillator, moderate/severe renal or hepatic impairment, were excluded from the analysis. A complete medical history was obtained from all study volunteers, and both groups underwent clinical examination and calculation of the $\mathrm{CHA}_{2} \mathrm{DS}_{2}$-VASc score. Eventually, 33 patients with a PAF history and 56 controls fulfilled inclusion criteria. The baseline characteristics of the two groups can be found in Table 1.

Table 1. Baseline characteristics of study participants.

\begin{tabular}{cccc}
\hline Patient Parameters & PAF $(\boldsymbol{n}=\mathbf{3 3})$ & Healthy $(\boldsymbol{n}=\mathbf{5 6})$ & $\boldsymbol{p}$ Value \\
\hline Age & $55.4 \pm 12.6$ & $55.2 \pm 5.7$ & 0.933 \\
Male sex $(\%)$ & $24(72.7)$ & $38(67.9)$ & 0.812 \\
Body mass index $\left(\mathrm{kg} / \mathrm{m}^{2}\right)$ & $28.2 \pm 4.6$ & $26.3 \pm 5.9$ & 0.756 \\
Hypertension $(\%)$ & $14(42.4)$ & $12(21.4)$ & 0.053 \\
Diabetes $(\%)$ & $0(0.0)$ & $1(1.8)$ & 1.000 \\
Dyslipidemia $(\%)$ & $10(30.3)$ & $14(25.0)$ & 0.626 \\
$\mathrm{CHA}_{2} \mathrm{DS}_{2}$-VASc score & $1.2 \pm 1.3$ & $0.7 \pm 0.8$ & 0.123 \\
\hline
\end{tabular}

Independent samples Mann-Whitney $U$ test, Fisher's exact test. Continues variables are reported mean \pm SD. Categorical variables are reported $n(\%)$.

Standard 12-lead ECGs were obtained from all participants. The recordings were performed at least 7 days apart from any AF episode to minimize the potential effect of myocardial stunning. The ECGs were scanned, stored in digital format, magnified suffi- 
ciently, and analyzed with digital image processing software (imagej.nih.gov/ij, accessed on 21 October 2020). Additionally, three-orthogonal axis system (X-frontal, Y-vertical, and Z-sagittal axis) vectorcardiographic (VCG) signals of $10 \mathrm{~min}$ duration were also recorded at the same time, with study individuals resting in the supine position, using a high sampling rate $(1000 \mathrm{~Hz})$ Galix GBI-3S Holter monitor.

All participants were informed about the scope of the study and gave written informed consent. The study complied with the Declaration of Helsinki and was approved by the Special Purpose General Assembly of Aristotle University School of Medicine (\#8, approved on 9 September 2016).

\subsection{Standard P-Wave Indices}

\subsubsection{The 12-Lead ECG Indices}

Eight conventional 12 lead ECG PWIs, PR duration, P-wave duration, P-wave dispersion, $\mathrm{P}$-wave peak time, $\mathrm{P}$-wave axis, $\mathrm{P}$-wave voltage in lead $\mathrm{I}, \mathrm{PTFV}_{1}$, and $\mathrm{P}$-wave area were measured by three observers, and mean values were calculated. P-wave dispersion was defined as the difference between the longest, and the shortest P-wave duration measured in any of the standard ECG leads. P-wave peak time is a novel index, equal to the duration between the beginning and peak of the P-wave measured in leads II or $\mathrm{V}_{1}$ [11]. An abnormal $\mathrm{P}$-wave axis was determined as a frontal $\mathrm{P}$-wave axis less than $0^{\circ}$ or more than $75^{\circ}$ [3], while $\mathrm{PTFV}_{1}$ was calculated as the amplitude-duration product of the terminal negative component of the $\mathrm{P}$-wave in lead $\mathrm{V}_{1}$ [12]. P-wave area $(\mathrm{mV} \times \mathrm{ms})$ was measured as the sum of the absolute areas underneath the positive and negative P-wave deflections, and the maximum area from among the 12 leads was selected [3].

Furthermore, P-wave biphasicity in inferior leads was assessed to identify IAB type [13]. Partial-IAB ( $\mathrm{p}$-IAB) was defined as a P-wave $\geq 120 \mathrm{~ms}$ without a negative deflection in the inferior leads (II, III, aVF), and advanced IAB (a-IAB) as a P-wave $\geq 120 \mathrm{~ms}$, along with biphasic morphology in inferior leads. Finally, a relatively new composite score, the MVP score (morphology-voltage-P-wave duration), was calculated, assigning up to two points to each of the three components [14] (Appendices A.1.1-A.1.7).

\subsubsection{Orthogonal Morphology}

Orthogonal P-wave morphology was accessed according to $\mathrm{P}$-wave positive/negative deflection, or biphasicity, in leads X, Y, and Z. Three predefined types (orthogonal type 1, 2, or 3) indicative of the interatrial conduction route were considered [15]. In types 1 and 2, leads $X$ and $Y$ are positive, and lead $Z$ is either negative or biphasic, while in type 3 lead $X$ is positive and lead $Y$ is biphasic. (Appendix A.1.8).

In conclusion, a total of fourteen SPWIs was taken into consideration; the eight conventional 12 lead ECG PWIs, along with the MVP score, a-IAB, p-IAB, and orthogonal types 1-3.

\subsection{P-Wave Beat-to-Beat Analysis}

\subsubsection{Beat-to-Beat Classification into Main and Secondary Morphology}

Orthogonal vectorcardiograms were further studied to accomplish B2B analysis. Signal processing was performed using MATLAB R2015a, The MathWorks, Inc., Natick, MA, USA. Following an automated signal pre-processing procedure, consisting of denoising and QRS complex detection, artifacts and ectopic beats were removed in a semi-automated manner. According to a methodology previously described [9], where the existence of main and secondary P-wave morphologies was proposed, a clustering technique was used to classify P-waves into distinct groups of main, secondary, or other less frequent morphologies. Specifically, a signal window of $250 \mathrm{~ms}$ preceding every QRS complex, named $\mathrm{P}$ segment $\left(\mathrm{P}_{\mathrm{SEG}}\right)$, was defined. Following a k-means clustering method, the optimal number of clusters, which better classify the $P_{\text {SEGs }}$ was calculated, and every $P_{\text {SEG }}$ was allocated to a cluster. The mean morphology of the cluster containing most PSEGs was used as a template for the detection of the P-waves matching the main morphology. 
For the remaining $\mathrm{P}_{\mathrm{SEG}}$, following the same process once again, an additional P-wave template was extracted, to detect the P-waves allocated to the secondary morphology. The beats that did not match any of the morphologies were considered as other morphologies. Therefore, the secondary morphology was not extracted merely as the mean morphology of the P-waves not matching the main morphology, but rather as the mean values of a group of beats highly correlated and truly forming a cluster. Finally, the percentage of P-waves matching the main and the secondary morphology in each lead was calculated, as well as the percentage of P-waves following simultaneously the main morphology in all three leads (Appendix A.2.1).

\subsubsection{Time-Domain Analysis}

Time features regarding P-wave position related to the QRS complex were calculated. Thus, the distance between P-wave onset, offset, and maximum value, and Q- or R-points were assessed for every beat allocated to the main morphology.

\subsubsection{Time-Frequency Domain Analysis}

The P-waves of the dominant morphology were further analyzed in a B2B aspect using continuous wavelet transform, an approach already been used for processing nonstationary signals such as ECG. The base wavelet used was the complex Morlet wavelet. According to a previous study of ours, where optimal frequency zone range was investigated, analysis was performed in three non-overlapping bands (low-L: $30-70 \mathrm{~Hz}$, medium-M: 70-160 Hz, and high-H: 160-200 Hz) [9]. Frequency features such as mean, median, and maximum energy, as well as time-frequency features, such as maximum energy location regarding P-wave onset, offset, or peak, were calculated (Appendix A.2.2).

Eventually, P-wave B2B analysis, consisting of classification into primary and secondary morphology, and time-domain and time-frequency domain analyses, in three different axes, in three individual frequency zones, and both mean value and coefficient of variation calculation of selected variables ended up to a total of 262 features (Table 2).

Table 2. Feature categories derived from beat-to-beat analysis.

\begin{tabular}{|c|c|c|c|c|}
\hline Beat-to-Beat Analysis Features & Leads & Freq. Zones & Mean/cv & Subtotal \\
\hline Percentage of P-waves matching main morphology & 3 & - & 1 & 3 \\
\hline Percentage of P-waves matching secondary morphology & 3 & - & 1 & 3 \\
\hline Secondary to main P-waves ratio & 3 & - & 1 & 3 \\
\hline $\begin{array}{l}\text { Percentage of P-waves matching main morphology in all axes at the } \\
\text { same time }\end{array}$ & 1 & - & 1 & 1 \\
\hline Distance between P-wave onset to R-wave & 3 & - & 2 & 6 \\
\hline Distance between P-wave onset to Q-wave & 3 & - & 2 & 6 \\
\hline Distance between P-wave peak to R-wave & 3 & - & 2 & 6 \\
\hline Distance between $\mathrm{P}$-wave peak to Q-wave & 3 & - & 2 & 6 \\
\hline Distance between P-wave offset to R-wave & 3 & - & 2 & 6 \\
\hline Distance between P-wave offset to Q-wave & 3 & - & 2 & 6 \\
\hline Distance between P-wave onset to P-wave peak & 3 & - & 2 & 6 \\
\hline Distance between P-wave onset to P-wave peak/P-wave duration & 3 & - & 2 & 6 \\
\hline Distance between P-wave peak to P-wave offset & 3 & - & 2 & 6 \\
\hline Distance between P-wave onset and maximum energy location & 3 & 3 & 2 & 18 \\
\hline $\begin{array}{c}\text { Distance between P-wave onset and maximum energy location } \\
\text { normalized to P-wave duration }\end{array}$ & 3 & 3 & 2 & 18 \\
\hline Distance between maximum energy location and P-wave offset & 3 & 3 & 2 & 18 \\
\hline Distance between maximum energy location and R-wave & 3 & 3 & 2 & 18 \\
\hline Distance between maximum energy location and Q-wave & 3 & 3 & 2 & 18 \\
\hline Distance between P-wave peak and maximum energy location & 3 & 3 & 2 & 18 \\
\hline Maximum energy value & 3 & 3 & 2 & 18 \\
\hline
\end{tabular}


Table 2. Cont

\begin{tabular}{|c|c|c|c|c|}
\hline Beat-to-Beat Analysis Features & Leads & Freq. Zones & Mean/cv & Subtotal \\
\hline Mean energy value & 3 & 3 & 2 & 18 \\
\hline Mean energy value normalized to P-wave duration & 3 & 3 & 2 & 18 \\
\hline Median energy value & 3 & 3 & 2 & 18 \\
\hline Median energy value normalized to P-wave duration & 3 & 3 & 2 & 18 \\
\hline Total & & & & 262 \\
\hline
\end{tabular}

Features derived from beat-to-beat P-wave morphology and wavelet analysis. Abbreviations: leads (orthogonal leads X, Y, Z; freq. zone: frequency zones (low, mid, and high); mean: mean value; cv: coefficient of variation (SD/mean).

\subsection{Statistical Analysis}

Statistical analysis data were expressed as mean \pm standard deviation for continuous variables. The Mann-Whitney $U$ test or the Fisher's exact test was used, as appropriate, for statistical testing. Univariate logistic regression analysis was performed on statistically significant features to determine variables with prognostic value on detecting patients with a history of AF, and variables were ranked according to their area under the curve (AUC). Predictors were checked for collinearity, and the features with the highest AUC among those highly correlated were selected for further study.

Following multivariate logistic regression analysis, two different classifiers were developed-one based on features derived from B2B analysis and one using SPWIs. Receiver operating characteristics (ROC) curves were delineated for these classifiers, and the AUC was calculated to estimate the predictive value of each one. AUC comparison was accomplished using DeLong's method [16]. Statistical analysis was performed using MATLAB (R2015a) computer software, and an alpha level of $<0.05$ was accepted as statistically significant.

\section{Results}

The studied dataset consisted of 276 features in total; of those, 262 variables were obtained from B2B analysis and 14 from SPWIs. Five SPWIs were found significantly different between the two groups, while B2B analysis was represented by nineteen statistically significant features; seven of them were derived from the percentage of main or secondary morphologies and twelve from spectral and temporal analysis (Table 3).

Table 3. P-wave indices and beat-to-beat variables in PAF patients and healthy controls.

\begin{tabular}{lccc}
\hline Features & Healthy $(\boldsymbol{n}=\mathbf{5 6})$ & AF $(\boldsymbol{n}=\mathbf{3 3})$ & $\boldsymbol{p}$ Value \\
\hline Standard P-wave indices & & & \\
\hline P-wave area $(\mathrm{ms} \times \mathrm{mV})$ & $11.1 \pm 4.5$ & $8.7 \pm 6.6$ & 0.025 \\
P-wave duration $(\mathrm{ms})$ & $112.2 \pm 16.2$ & $122.6 \pm 19.5$ & 0.006 \\
Partial Interatrial Block & $8(14.3 \%)$ & $14(42.4 \%)$ & 0.003 \\
P-wave voltage in lead I $\left(\mathrm{mV} \times 10^{-3}\right)$ & $145.3 \pm 50.5$ & $110.4 \pm 56.1$ & 0.005 \\
MVP ECG score & $2.036 \pm 1.436$ & $3.000 \pm 1.561$ & 0.005 \\
PR duration (ms) & $182.6 \pm 18.8$ & $183.9 \pm 27.5$ & 0.763 \\
P-wave dispersion $(\mathrm{ms})$ & $25.1 \pm 14.5$ & $24.2 \pm 13.2$ & 0.799 \\
P-wave peak time & $67.9 \pm 9.7$ & $69.1 \pm 20.6$ & 0.349 \\
P-wave axis & $47.1 \pm 31.5$ & $53.6 \pm 22.3$ & 0.075 \\
P-wave Terminal Force in lead $\mathrm{V}_{1}(\mathrm{~ms} \times \mathrm{mV})$ & $5.1 \pm 4.5$ & $5.2 \pm 5.5$ & 0.555 \\
P-wave Terminal Force in lead $\mathrm{V}_{1}>4 \mathrm{~ms} \times \mathrm{mV}$ & $18(32.1 \%)$ & $10(30.3 \%)$ & 0.857 \\
Advanced Interatrial Block & $11(19.6 \%)$ & $6(18.2 \%)$ & 0.866 \\
Orthogonal type 1 & $14(25.0 \%)$ & $6(18.2 \%)$ & 0.457 \\
Orthogonal type 2 & $39(69.6 \%)$ & $22(66.7 \%)$ & 0.770 \\
Orthogonal type 3 & $3(5.4 \%)$ & $2(6.1 \%)$ & 0.889 \\
\hline
\end{tabular}


Table 3. Cont.

\begin{tabular}{|c|c|c|c|}
\hline Features & Healthy $(n=56)$ & $\mathrm{AF}(n=33)$ & $p$ Value \\
\hline \multicolumn{4}{|l|}{ Beat-to-beat analysis } \\
\hline \multicolumn{4}{|l|}{ Morphologies (\%) } \\
\hline P-waves matching main morphology-X & $99.7 \pm 0.8$ & $96.6 \pm 6.4$ & $<0.001$ \\
\hline P-waves matching main morphology-Y & $99.0 \pm 3.8$ & $95.8 \pm 8.0$ & $<0.001$ \\
\hline P-waves matching secondary morphology-X & $0.2 \pm 0.6$ & $1.5 \pm 3.1$ & $<0.001$ \\
\hline P-waves matching secondary morphology-Y & $0.4 \pm 1.4$ & $2.0 \pm 4.6$ & 0.017 \\
\hline $\begin{array}{l}\text { P-waves matching main morphology-all leads } \\
\text { simultaneously }\end{array}$ & $95.2 \pm 7.7$ & $89.1 \pm 12.3$ & 0.041 \\
\hline Secondary to main P-waves ratio-X & $0.002 \pm 0.006$ & $0.02 \pm 0.04$ & $<0.001$ \\
\hline Secondary to main P-waves ratio-Y & $0.005 \pm 0.02$ & $0.03 \pm 0.07$ & 0.016 \\
\hline \multicolumn{4}{|l|}{ Time domain (ms) } \\
\hline P-wave peak to R-wave-X, cv & $0.08 \pm 0.2$ & $0.1 \pm 0.08$ & $<0.001$ \\
\hline P-wave peak to Q-wave-X, cv & $0.03 \pm 0.4$ & $0.2 \pm 0.2$ & $<0.001$ \\
\hline P-wave onset to R-wave- $X, c v$ & $0.03 \pm 0.02$ & $0.05 \pm 0.04$ & 0.004 \\
\hline P-wave onset to Q-wave-X, cv & $0.04 \pm 0.02$ & $0.08 \pm 0.06$ & 0.004 \\
\hline P-wave onset to P-wave peak (peak time)-X, cv & $0.05 \pm 0.03$ & $0.08 \pm 0.06$ & $<0.001$ \\
\hline P-wave peak to P-wave offset-X, cv & $0.1 \pm 0.5$ & $0.09 \pm 0.06$ & $<0.001$ \\
\hline P-wave peak to P-wave offset-Y, cv & $0.05 \pm 0.03$ & $0.1 \pm 0.2$ & 0.041 \\
\hline \multicolumn{4}{|l|}{ Time-frequency domain (ms) } \\
\hline $\begin{array}{l}\text { Maximum energy location to P-wave offset-mid } \\
\text { band, } Z \text {, mean }\end{array}$ & $61.1 \pm 18.6$ & $53.8 \pm 20.1$ & 0.044 \\
\hline $\begin{array}{l}\text { Maximum energy location to P-wave onset, } \\
\text { normalized to P-wave duration-high band, } Z \text {, mean }\end{array}$ & $0.6 \pm 0.1$ & $0.6 \pm 0.09$ & 0.049 \\
\hline $\begin{array}{l}\text { Maximum energy location to P-wave onset, } \\
\text { normalized to P-wave duration-mid band, } \mathrm{Z} \text {, mean }\end{array}$ & $0.6 \pm 0.1$ & $0.6 \pm 0.1$ & 0.034 \\
\hline \multicolumn{4}{|l|}{ Frequency domain $\left(\mu \mathrm{V}^{2}\right)$} \\
\hline Maximum energy-high band, Y, mean & $0.2 \pm 0.1$ & $0.1 \pm 0.09$ & 0.003 \\
\hline Maximum energy-high band, $\mathrm{Y}, \mathrm{cv}$ & $0.5 \pm 0.1$ & $0.4 \pm 0.2$ & 0.028 \\
\hline
\end{tabular}

Continuous variables are reported as mean \pm SD. Categorical variables are reported as $n$ (\%). In beat-to-beat analysis, only variables with a significant value of $p<0.05$ are reported. Abbreviations: $\mathrm{cv}$ : coefficient of variation; X, Y, Z: orthogonal leads X, Y, Z.

Nine traditional PWIs did not differ significantly between the two groups: PR duration, $\mathrm{P}$-wave dispersion, $\mathrm{P}$-wave peak time, $\mathrm{P}$-wave axis, $\mathrm{PTFV}_{1}, \mathrm{P}$-wave orthogonal type, and a-IAB values were comparable in control and PAF groups. On the other hand, the widely used P-wave duration was longer, and the P-wave area, along with P-wave voltage in lead I were smaller in PAF patients, compared to the control group. Moreover, p-IAB was more common and the MVP score was higher in the PAF group.

Additionally, morphology analysis revealed significant differences between main, secondary, and secondary to the main ratio in both axis $\mathrm{X}$ and $\mathrm{Y}$, along with the percentage of P-waves following main morphology in all leads at the same time. Furthermore, both time-domain features and frequency-derived parameters in all three axes were represented by significant variables such as coefficient of variation of $P$-wave peak time in axis $X$, mean value of maximum energy in the high-frequency band in axis $Y$, or mean value of maximum energy location to P-wave duration in the mid-frequency band in axis $\mathrm{Z}$.

Following univariate logistic regression analysis, variables were ranked according to estimated AUC, and odds ratios (OR) were calculated. Sixteen features were significant predictors, while eight variables did not reach the level of significance or AUC lower limit above 0.5 and were excluded from further analysis (Table 4). 
Table 4. Univariate regression analysis of potential prognostic factors on the presence of atrial fibrillation.

\begin{tabular}{|c|c|c|c|c|c|c|c|}
\hline Rank & Feature & Type & AUC & AUC Limits & OR & $95 \% \mathrm{CI}$ & $p$ Value \\
\hline 1 & Peak time- $-\mathrm{X}, \mathrm{cv}$ & $\mathrm{B} 2 \mathrm{~B}$ & 0.726 & $0.606-0.846$ & 2.672 & $1.463-4.880$ & 0.001 \\
\hline 2 & $\begin{array}{c}\text { P-wave peak to } \\
\text { Q-wave-X, cv }\end{array}$ & B2B & 0.725 & $0.614-0.836$ & 33.513 & $\begin{array}{c}3.904- \\
287.692\end{array}$ & 0.001 \\
\hline 3 & Main morphology $\%-Y$ & B2B & 0.723 & $0.616-0.830$ & 0.553 & $0.307-0.996$ & 0.048 \\
\hline 4 & $\begin{array}{c}\text { P-wave peak to } \\
\text { R-wave-X, cv }\end{array}$ & B2B & 0.716 & $0.598-0.834$ & 1.130 & $0.733-1.742$ & 0.581 \\
\hline 5 & $\begin{array}{c}\text { P-wave peak to P-wave } \\
\text { offset- } X, c v\end{array}$ & B2B & 0.710 & $0.590-0.830$ & 0.935 & $0.574-1.523$ & 0.788 \\
\hline 6 & Main morphology \%-X & $\mathrm{B} 2 \mathrm{~B}$ & 0.698 & $0.582-0.813$ & 0.081 & $0.015-0.434$ & 0.003 \\
\hline 7 & $\begin{array}{c}\text { Max energy-high band, } \\
\text { Y, mean }\end{array}$ & B2B & 0.681 & $0.562-0.799$ & 0.550 & $0.326-0.930$ & 0.026 \\
\hline 8 & $\begin{array}{c}\text { P-wave onset to } \\
\text { Q-wave-X, cv }\end{array}$ & B2B & 0.679 & $0.562-0.796$ & 2.542 & $1.421-4.547$ & 0.002 \\
\hline 9 & P-wave voltage in lead I & SPWI & 0.679 & $0.558-0.800$ & 0.493 & $0.300-0.810$ & 0.005 \\
\hline 10 & $\begin{array}{l}\text { * Secondary to main } \\
\text { morphology ratio } \%-X\end{array}$ & $\mathrm{~B} 2 \mathrm{~B}$ & 0.679 & $0.586-0.771$ & 7.525 & $1.638-34.562$ & 0.009 \\
\hline 11 & $\begin{array}{c}\text { * Secondary morphology } \\
\%-X\end{array}$ & B2B & 0.678 & $0.585-0.771$ & 4.897 & $1.503-15.959$ & 0.008 \\
\hline 12 & $\begin{array}{c}* \text { P-wave onset to } \\
\text { R-wave- } X, c v\end{array}$ & B2B & 0.676 & $0.556-0.796$ & 2.399 & $1.331-4.324$ & 0.004 \\
\hline 13 & P-wave duration & SPWI & 0.675 & $0.555-0.795$ & 1.842 & $1.150-2.950$ & 0.011 \\
\hline 14 & ${ }^{*}$ MVP score & SPWI & 0.673 & $0.560-0.787$ & 1.921 & $1.209-3.052$ & 0.006 \\
\hline 15 & P-wave area & SPWI & 0.653 & $0.528-0.779$ & 0.587 & $0.357-0.964$ & 0.035 \\
\hline 16 & Partial Interatrial Block & SPWI & 0.641 & $0.543-0.738$ & 1.906 & $1.225-2.964$ & 0.004 \\
\hline 17 & $\begin{array}{l}\text { Max energy-high } \\
\text { band-Y, cv }\end{array}$ & B2B & 0.640 & $0.510-0.770$ & 0.704 & $0.438-1.130$ & 0.146 \\
\hline 18 & $\begin{array}{l}\text { Max energy location to } \\
\text { Pdur.-mid band, Z, } \\
\text { mean }\end{array}$ & B2B & 0.633 & $0.510-0.756$ & 1.680 & $1.024-2.755$ & 0.040 \\
\hline 19 & $\begin{array}{l}\text { Main morphology } \% \text {-all } \\
\text { axes }\end{array}$ & B2B & 0.631 & $0.500-0.761$ & 0.527 & $0.326-0.851$ & 0.009 \\
\hline 20 & $\begin{array}{c}\text { Max energy location to } \mathrm{P} \\
\text { offset-mid band, } \mathrm{Z}, \\
\text { mean }\end{array}$ & B2B & 0.630 & $0.506-0.755$ & 0.668 & $0.420-1.062$ & 0.088 \\
\hline 21 & $\begin{array}{l}\text { Max energy location to } \\
\text { Pdur.-high band, Z, } \\
\text { mean }\end{array}$ & B2B & 0.624 & $0.502-0.746$ & 1.575 & $0.973-2.551$ & 0.065 \\
\hline 22 & $\begin{array}{l}\text { P-wave peak to P-wave } \\
\text { offset time-Y, } \mathrm{cv}\end{array}$ & B2B & 0.620 & $0.496-0.743$ & 6.590 & $0.953-45.565$ & 0.056 \\
\hline 23 & $\begin{array}{l}\text { Secondary to main } \\
\text { morphology ratio } \%-Y\end{array}$ & B2B & 0.600 & $0.505-0.695$ & 1.933 & $0.868-4.306$ & 0.107 \\
\hline 24 & $\begin{array}{l}\text { Secondary morphology } \\
\qquad \%-Y\end{array}$ & B2B & 0.600 & $0.504-0.695$ & 1.830 & $0.928-3.611$ & 0.081 \\
\hline
\end{tabular}

Features ranking according to AUC. Bold values denote statistical significance at the $p<0.05$ level. Features marked with an asterisk $\left({ }^{*}\right)$ were excluded from further analysis due to collinearity. Abbreviations: X, Y, Z: orthogonal leads X, Y, Z; Pdur.: P-wave duration; mean: mean value; cv: coefficient of variation; B2B: beat-to-beat feature; SPWI: standard P-wave index; AUC: area under the curve; OR: odds ratio; CI: confidence interval.

Collinearity test revealed a strong correlation between main, secondary, and secondary to main morphology ratio in axis $X$, between the coefficient of variation of the distance between $\mathrm{P}$-wave onset and the Q- or R-wave in axis $\mathrm{X}$, and between the MVP score and $P$-wave duration. Only the features with the highest AUC among those highly correlated were selected (Table 4). Thus, eight B2B features and four SPWIs were finally used in multivariable regression analysis. Eventually, two classifier groups were developed: one using SPWIs and one using B2B variables. The risk of overfitting was kept low by ensuring an event-per-variable ratio above 10 , and thus, only models consisting of $\leq 3$ compounds were taken into consideration [17]. 
All suggested models for each category were compared to each other in terms of AUC, and those with the highest performance in our data sample were selected (Table 5). In the first case, a B2B classifier consisting of the following three features was proposed: (i) coefficient of variation of distance between the P-wave peak and Q-wave in X axis, (ii) percentage of $P$-waves allocated in main morphology in $X$ axis, and (iii) mean value of maximum energy in the high-frequency band in the $Y$ axis. In the second case, the model with the highest AUC among all SPWIs classifiers consisted of (i) p-IAB, (ii) P-wave voltage in lead I, and (iii) P-wave duration.

Table 5. Multivariate analysis characteristics of logistic regression-based classifiers.

\begin{tabular}{llccc}
\hline Classifier & Variables & OR & 95\% CI & $p$ Value \\
\hline \multirow{3}{*}{ Beat-to-beat analysis } & P-wave peak to Q-wave-X, cv & 1.541 & $0.993-2.394$ & 0.054 \\
& Main morphology \%-X & 0.786 & $0.624-0.991$ & 0.042 \\
& Max energy-high frequency band, Y, mean & 0.443 & $0.187-1.048$ & 0.064 \\
\hline \multirow{3}{*}{ Standard P-wave indices } & Partial Interatrial Block & 1.979 & $0.550-7.122$ & 0.296 \\
& Voltage in lead I & 0.435 & $0.203-0.931$ & 0.032 \\
& P-wave duration & 1.736 & $0.828-3.640$ & 0.144 \\
\hline
\end{tabular}

Abbreviations: X, Y: orthogonal leads X, Y; cv: coefficient of variation; OR: odds ratio; CI: confidence interval.

These two classifiers were finally compared to each other, and the B2B model was found superior to the SPWIs model: B2B AUC: 0.849 (0.754-0.917) vs. SPWIs AUC: 0.721 (0.613-0.813), $p$ value: 0.041 (Figure 1).

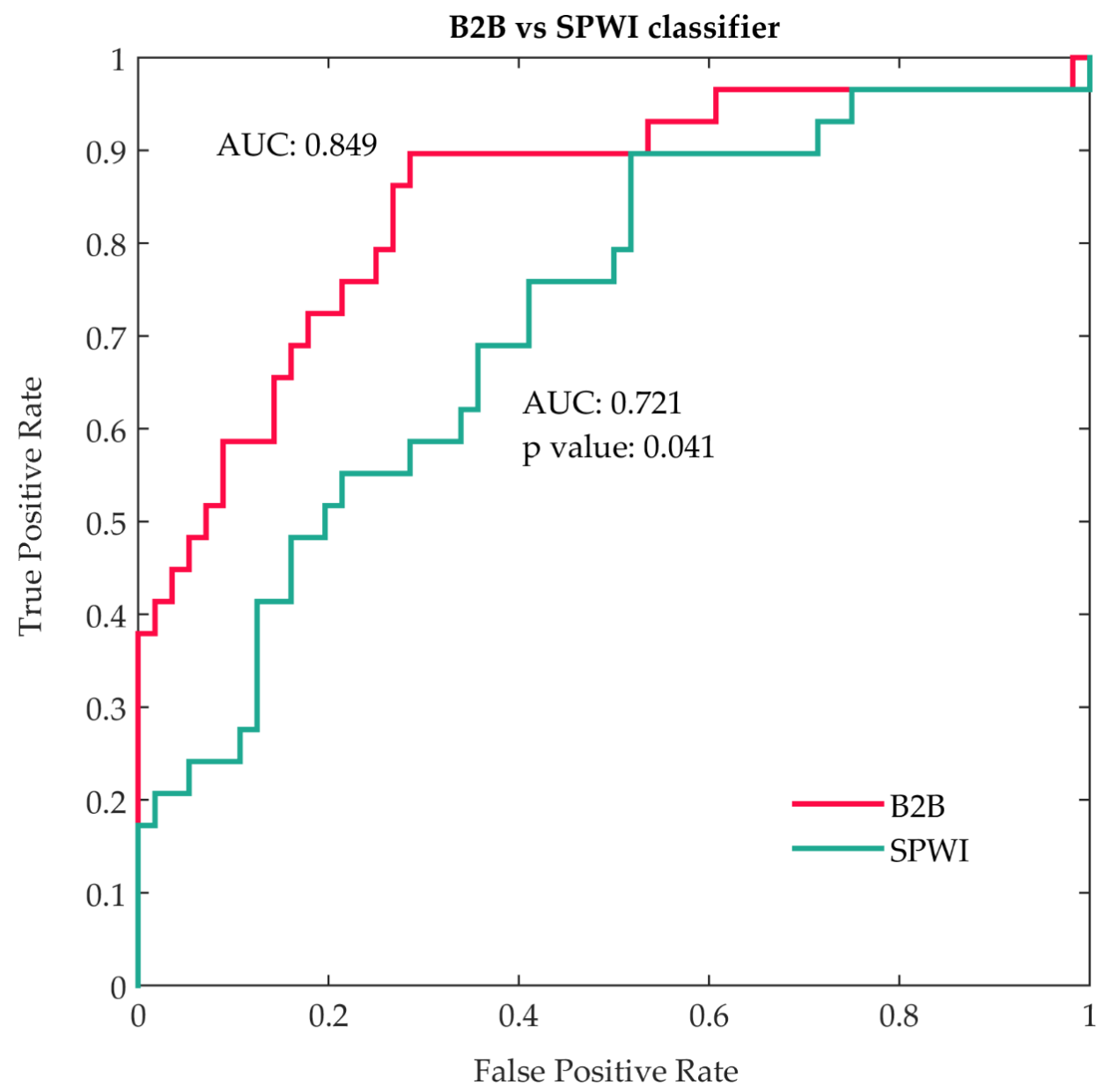

Figure 1. Comparison between beat-to-beat and standard P-wave indices classifiers. Abbreviations: B2B: beat to beat; SPWI: standard P-wave indices; AUC: area under the curve. 


\section{Discussion}

In the current study, we assessed the performance of B2B P-wave analysis in distinguishing PAF patients from individuals with no history of AF, compared to that of standard PWIs. In our sample, a B2B-derived model outperformed a classifier based on established ECG-based PAF predictors.

Univariate analysis revealed that only B2B indices, and none SPWI, achieved an acceptable AUC > 0.7 in predicting PAF (Table 4). Furthermore, the B2B classifier consists of three components coming from three different fields of $\mathrm{B} 2 \mathrm{~B}$ analysis: main and secondary morphology analysis (percentage of P-waves allocated in main morphology in X axis), temporal analysis (coefficient of variation of distance between the P-wave peak and Q-wave in $\mathrm{X}$ axis), and wavelet analysis of main $\mathrm{P}$-wave morphology (mean value of maximum energy in the high-frequency band in the $\mathrm{Y}$ axis), underlying the importance of an integrated approach to PAF prediction. Additionally, the SPWI classifier consists of p-IAB, voltage in lead I, and P-wave duration, features that, interestingly, are also compounds of the recently developed MVP score [14].

Many PWIs have been previously found to be highly correlated to AF development. Pwave duration may be the most widely studied among them. In our study, P-wave duration along with voltage in lead I, and patrial IAB was one of the variables included in the SPWI classifier. In a meta-analysis of Framingham Heart Study (FHS) and Atherosclerosis Risk in Communities (ARIC) study, P-wave duration > $120 \mathrm{~ms}$ was significantly associated with AF [18]. Moreover, low P-wave amplitude in lead I has been related to displaced interatrial conduction and AF recurrence in another study [19].

Additionally, in the aforementioned work, the P-wave area did not show a robust correlation with AF, and $\mathrm{PTFV}_{1}$ predicted AF only in the ARIC study and not in FHS [18]. However, $\mathrm{PTFV}_{1}$ has been found in other studies to be significantly associated with AF occurrence [3,12] but not in ours.

Advanced interatrial block (a-IAB) is an established electrocardiographic phenotype, that has been thoroughly studied. However, in Regicor Study it was found that a-IAB did not seem to provide an additional AF risk beyond that of P-wave duration [20], which was concordant with our findings. Risk factors for developing a-IAB such as aging, hypertension, and obesity are similar to those for developing $\mathrm{AF}$, interpreting the relationship between a-IAB and AF [20]. Since, patients selected in our study were relatively young, with a short history of PAF and few other comorbidities, there were very few cases of a-IAB, not enough to support a statistically significant result. On the contrary, p-IAB was found to be a quite powerful predictor and thus was included in the proposed SPWI classifier.

One of the novelties in our work is the study of P-wave variability with means of B2B analysis. Most previous studies on P-wave analysis were conducted on $10 \mathrm{~s}$ ECG recordings or signal-averaged ECGs. However, a B2B approach on a P-wave study is feasible and effective [21,22]. In fact, in our study, not only we managed to observe P-wave variability in 10 min recordings, but we also succeeded in depicting and quantifying primary and secondary morphologies using an algorithm formerly described and repeatedly tested for consistency in various datasets. A higher percentage of recorded beats belonging to secondary morphologies and a lower percentage of beats of dominant morphology, in various orthogonal axes, were strongly associated with PAF, both in the current dataset and in a different dataset, previously studied [9]. This P-wave variability can only be reliably quantified in relatively lengthy ECG recordings such as the ones we use in the current study and could be proved to be the main advantage of the proposed modality. In fact, since the whole process is largely automated, the workload required to analyze a 10-minute recording is considerably low.

In addition, it is of great importance to underline that the patients who participated in our work had a noticeably short history of PAF (less than a month), were relatively young (mean age: $55.4 \pm 12.6)$, and had a low $\mathrm{CHA}_{2} \mathrm{DS}_{2}$-VASc score $(1.2 \pm 1.3)$. Thus, using the proposed analysis it is feasible to detect predisposition to AF in the early stages. 
Similarly, impaired interatrial conduction, assessed utilizing orthogonal morphology type, has been observed in young patients without comorbidities, implying that alterations in atrial electrophysiology may be the cause rather than the consequence of AF [23]. Moreover, in our study, patients receiving antiarrhythmic drugs were excluded, so it is safe to conclude that there was no interference to results caused by antiarrhythmic medication.

The case-control design of this study is a relative limitation but considered acceptable for a study investigating a novel diagnostic modality. Larger sample size would probably provide more robust results. In this work, simple logistic regression was employed, but in the future, more sophisticated artificial intelligence-based classifiers trained with features derived from larger populations are expected to reach a higher level of accuracy.

Although a well-known ECG-derived AF predictor, signal-averaged ECG (SAECG) was not analyzed in the current study. Recording atrial late potentials is technically challenging; thus, the hypothesis that low-amplitude atrial potentials are associated with AF was initially rejected [24]. However, using improved techniques, several SAECG P-wave indices were studied. In fact, atrial SAECG is widely used to calculate filtered P-wave duration (FPD), a more precise and reproducible measure of P-wave duration. On the contrary, SAECG late potential parameters, such as root mean square voltage of terminal Pwave segments, supposed to represent the activation of the left pulmonary veins [25], have shown little reproducibility and their clinical importance is controversial [26]. Therefore, in patients with PAF, FPD was longer, compared to normal controls, while no statistical difference was found in atrial late potentials [27]. Furthermore, FDP can identify hypertensive PAF patients while in sinus rhythm [28] and, along with left atrial dimension, is considered significant predictor of transmission from paroxysmal to persistent or permanent AF $[29,30]$.

Platonov et al. have shown that fibrosis and fatty infiltration were more manifest in autopsies of patients with permanent $\mathrm{AF}$ than in those with paroxysmal $\mathrm{AF}$, regardless of patients' age [31]. Moreover, P-wave duration and amplitude show a significant correlation with low-voltage area size and may be used as a non-invasive tool to predict severe scarring, as experimental and simulation studies suggest [32,33]. Therefore, PWIs probably predict AF progression by reflecting atrial fibrosis extension. Furthermore, B2B P-wave variability in patients with paroxysmal AF could be explained by variability in sinoatrial node exit location in combination with slow conducting regions, such as scars, as has been shown in computational simulation studies [34,35].

In future studies, an association between B2B indices and AF predictors other than SPWIs can be examined. Thus, a correlation between B2B analysis and echocardiographic parameters of left atrial size and function or characteristics of the left atrial substrate such as low voltage areas would be a potential research topic. Moreover, prospective studies can be conducted to determine B2B predictors' ability to detect clinical conditions beyond $\mathrm{AF}$, such as embolic strokes of an undetermined source (ESUS).

\section{Conclusions}

Early identification of patients in the absence of organic heart disease or other predisposing factors, who are prone to PAF is a crucial issue for all health stakeholders. B2B $\mathrm{P}$-wave analysis is a novel, effective approach for early AF prediction and seems that it is superior to the conventional PWIs analysis. Larger datasets will be necessary to aid the development of artificial intelligence models based on this analysis, to accurately predict PAF during sinus rhythm.

Author Contributions: Conceptualization, D.T., D.F., and V.P.V.; methodology, C.B. and A.P.A.; software, D.F. and I.C.; validation, N.F., G.E., N.M., and D.G.T.; formal analysis, D.T., D.F., and I.C.; investigation, D.T., C.L., K.T., A.T., and D.M.; resources, V.P.V., I.C., and N.F.; data curation, D.T., D.F, A.T., and D.M.; writing — original draft preparation, D.T. and D.F.; writing—review and editing, V.P.V., I.C., A.T., and C.B.; visualization, D.T. and D.F.; supervision, V.P.V.; project administration, V.P.V.; funding acquisition, D.T. and V.P.V. All authors have read and agreed to the published version of the manuscript. 
Funding: This research was funded by the Hellenic Cardiological Society (HCS grant \#1/2017).

Institutional Review Board Statement: The study was conducted according to the guidelines of the Declaration of Helsinki and approved by the Special Purpose General Assembly of Aristotle University School of Medicine (8/9-2-2016, approved on 9 September 2016).

Informed Consent Statement: Informed consent was obtained from all subjects involved in the study.

Data Availability Statement: The data presented in this study are available on request from the corresponding author.

Conflicts of Interest: The authors declare no conflict of interest. The funders had no role in the design of the study; in the collection, analyses, or interpretation of data; in the writing of the manuscript, or in the decision to publish the results.

\section{Appendix A.}

Appendix A.1. Standard P-Wave Indices

Appendix A.1.1. Advanced Interatrial Block

The advanced interatrial block is defined as P-wave duration $>120 \mathrm{~ms}$ along with biphasic P-wave in inferior leads (Figure A1) [13].
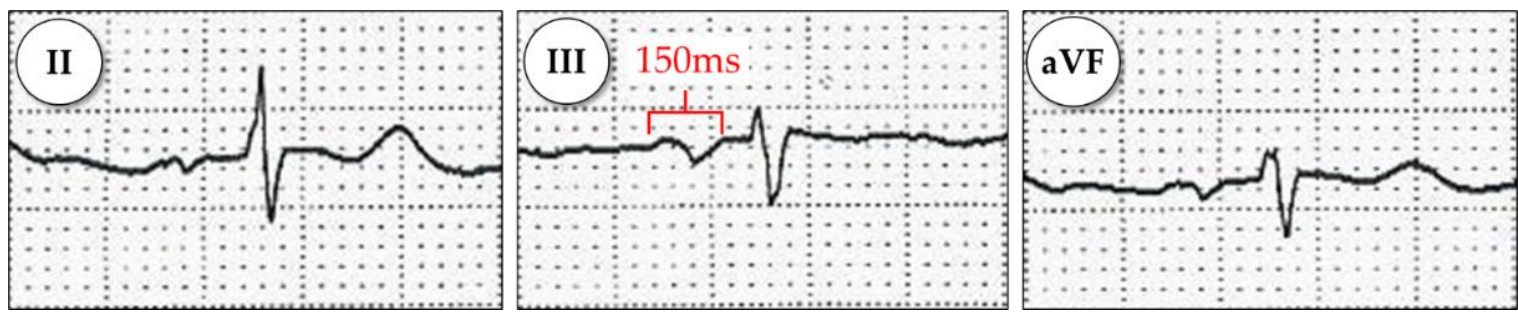

Figure A1. Advanced interatrial block. P-wave duration more than $120 \mathrm{~ms}$ along with biphasic P-wave in inferior leads II, III and aVF.

Appendix A.1.2. P-Wave Dispersion

$\mathrm{P}$-wave dispersion is defined as the difference between the longest and the shortest Pwave duration measured in any of the standard ECG leads (Figure A2). P-wave dispersion is expected to be increased in PAF.
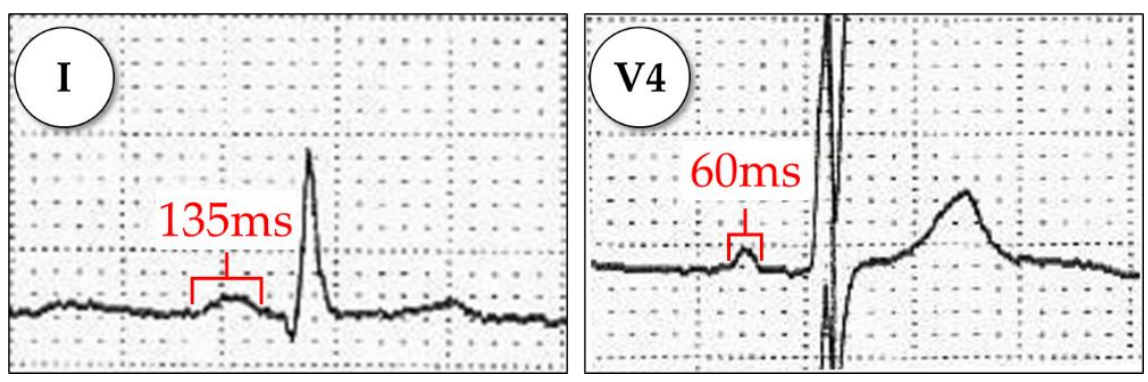

Figure A2. P-wave dispersion. In this case, $\mathrm{P}$-wave dispersion $=75 \mathrm{~ms}(135-60 \mathrm{~ms})$.

\section{Appendix A.1.3. P-Wave Area}

$\mathrm{P}$-wave area is calculated as the sum of the absolute areas underneath the positive and negative P-wave deflections, and the maximum area from among the 12 leads is selected (Figure A3). It is decreased in PAF, with a cut-off value of $4 \mathrm{mV} \times \mathrm{ms}$ [3]. 


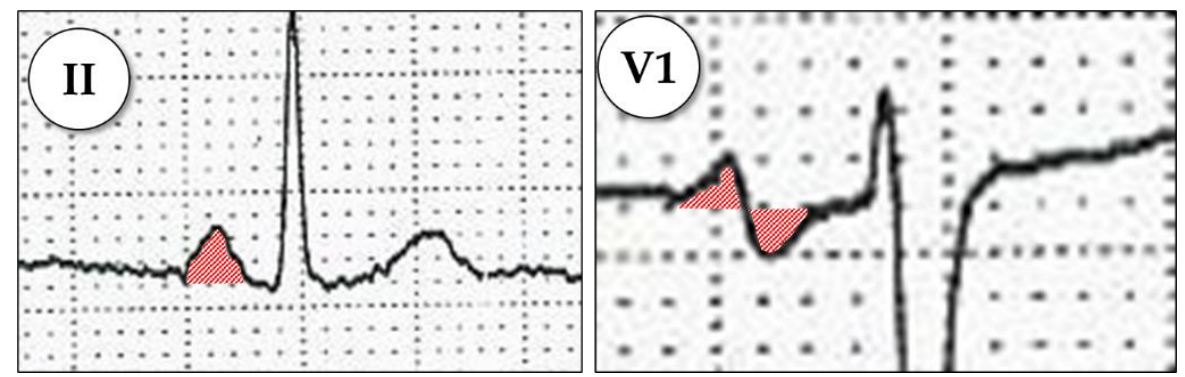

Figure A3. P-wave area depiction in lead II (monophasic) and lead $\mathrm{V}_{1}$ (biphasic).

Appendix A.1.4. P-Wave Terminal Force in V1 (PTFV1)

$\mathrm{PTFV}_{1}$ is calculated by multiplying the depth by the duration of the P-wave terminal negativity in $\mathrm{V}_{1}$ (Figure A4). A product of more than $4 \mathrm{mV} \times \mathrm{ms}$ is considered abnormal [12].

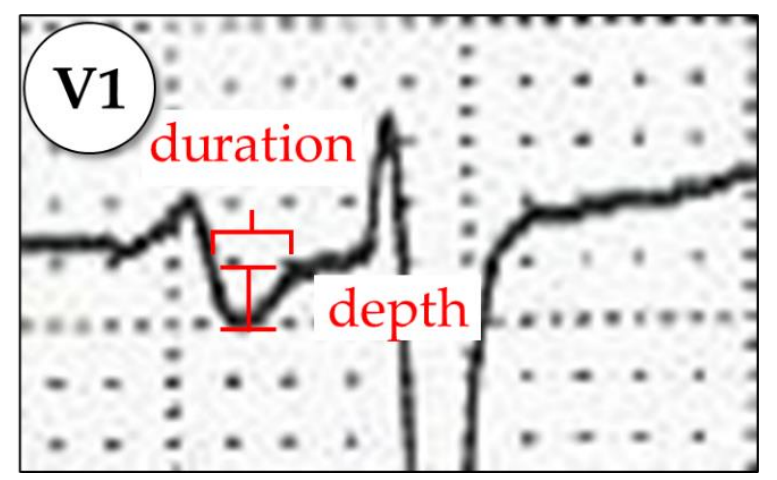

Figure A4. P-wave Terminal Force in V1 equals the product of negative deflection duration $\times$ depth.

Appendix A.1.5. P-Wave Axis

The P-wave axis is calculated in the frontal plane (Figure A5). Axis values between $0^{\circ}$ and $+75^{\circ}$ are considered to be normal [3].

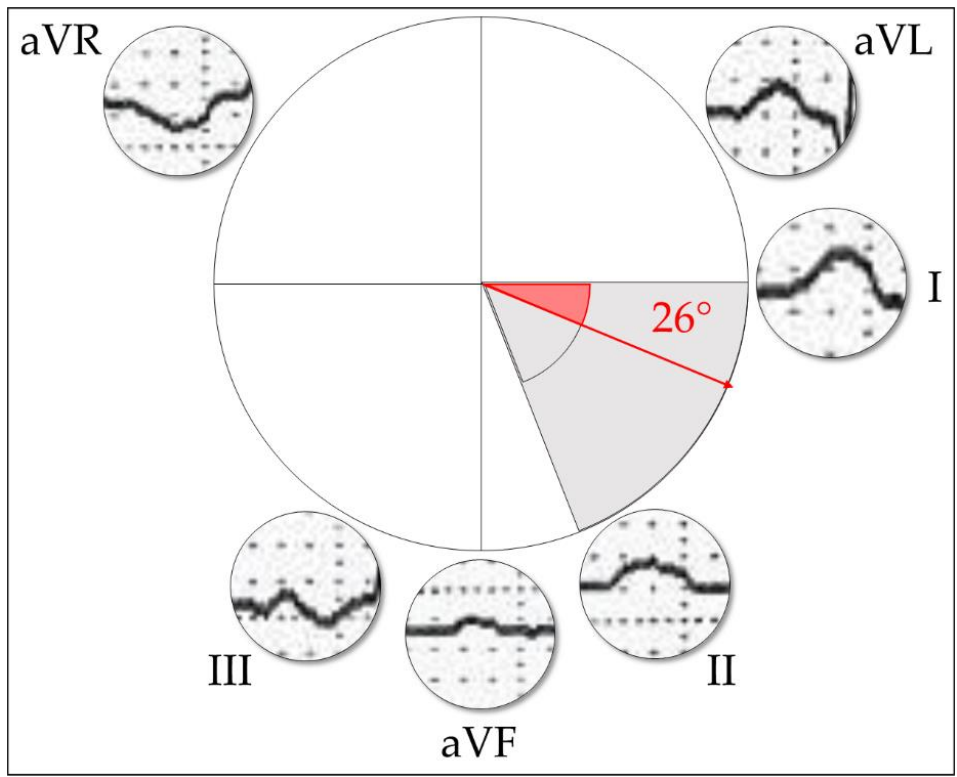

Figure A5. P-wave axis in the frontal plane. 
Appendix A.1.6. P-Wave Voltage in Lead I

P-wave voltage below $0.1 \mathrm{mV}$ in lead I is considered abnormal (Figure A6) [19].

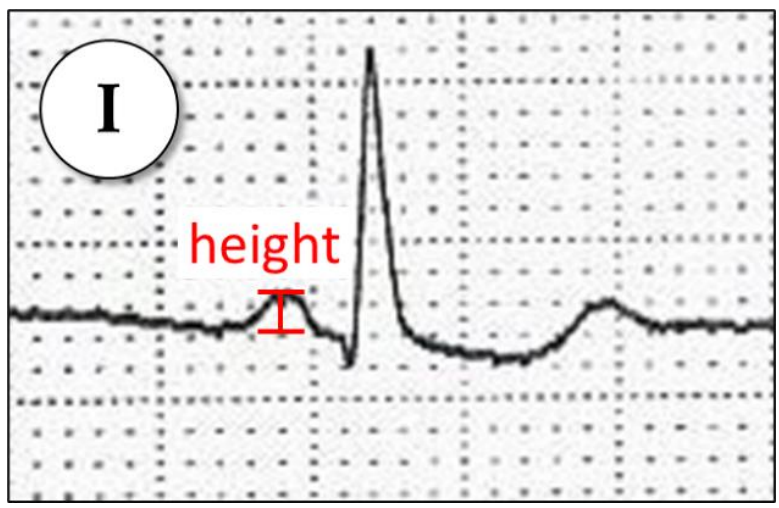

Figure A6. P-wave voltage in lead I.

Appendix A.1.7. MVP Score

The MVP score (Morphology-Voltage-P-wave duration) is calculated by assigning up to two points to each one of the three components (Table A1) [14].

Table A1. MVP score calculation.

\begin{tabular}{ccc}
\hline Variable & Value & Score \\
\hline \multirow{3}{*}{ Morphology in inferior leads } & Nonbiphasic $(<120 \mathrm{~ms})$ & 0 \\
& Nonbiphasic $(\geq 120 \mathrm{~ms})$ & 1 \\
& Biphasic & 2 \\
\hline \multirow{2}{*}{ Voltage in lead I } & $>0.2 \mathrm{mV}$ & 0 \\
& $0.10-0.20 \mathrm{mV}$ & 1 \\
& $<0.10 \mathrm{mV}$ & 2 \\
\hline \multirow{2}{*}{ P-wave duration } & $<120 \mathrm{~ms}$ & 0 \\
& $120-140 \mathrm{~ms}$ & 2 \\
\hline
\end{tabular}

0-2: low probability, 3-4: intermediate probability, and 5-6: high probability of AF.

Appendix A.1.8. Orthogonal Types 1, 2, or 3

In orthogonal types 1 and 2 , leads $X$ and $Y$ are positive, and lead $Z$ is either negative or biphasic. In type 3, lead $X$ is positive, and lead $Y$ is biphasic (Figure A7). Each type represents a different interatrial activation route, with type 3 being highly correlated to $\mathrm{AF}$ [15]. 


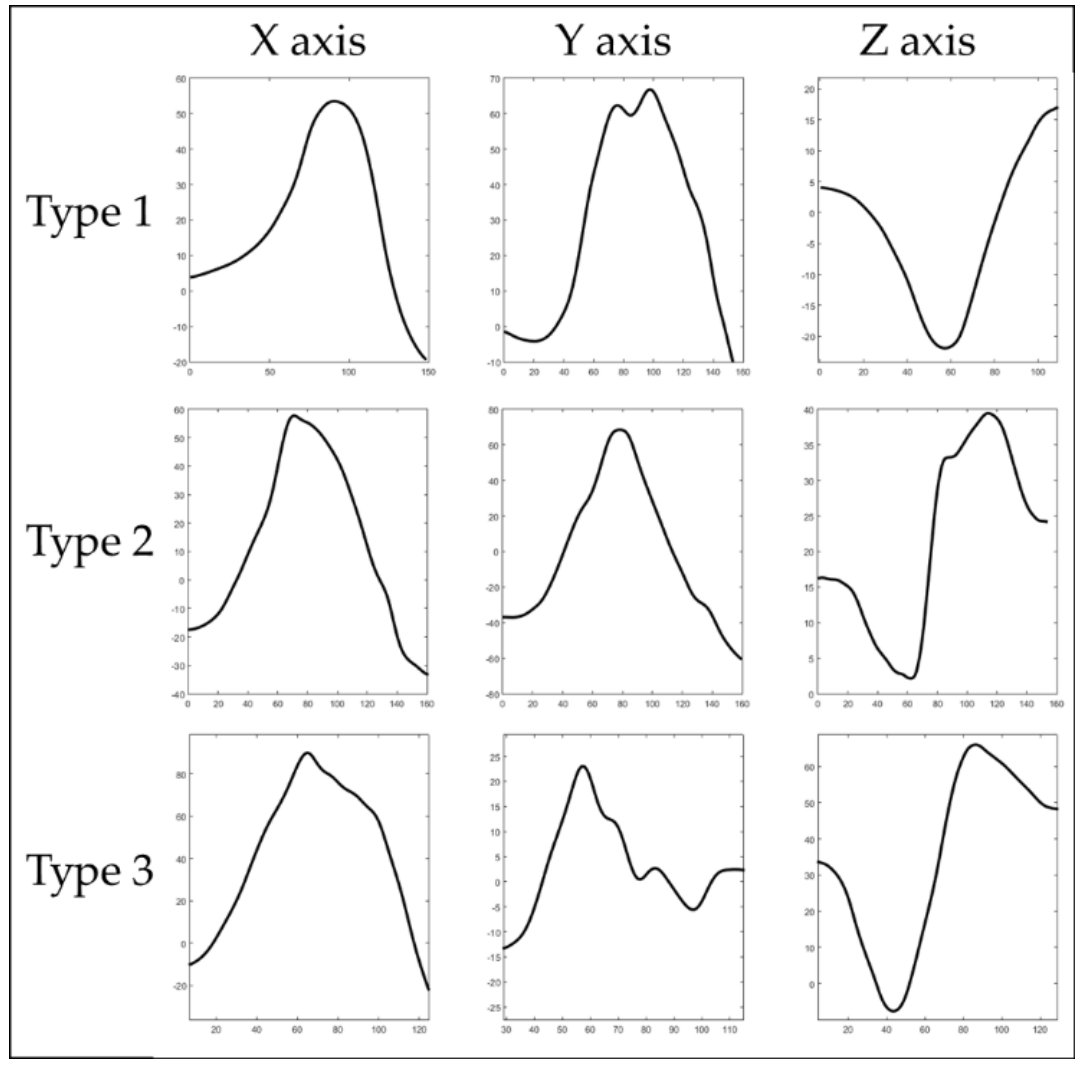

Figure A7. Orthogonal types 1, 2, and 3.

Appendix A.2. Beat-to-Beat Analysis

Appendix A.2.1. Main and Secondary Morphologies

Following a clustering procedure, each P-wave is allocated to main, secondary, or other less common morphologies (Figure A8). In people suffering from AF, the percentage of P-waves allocated in main morphology is smaller than in healthy individuals. On the contrary, P-waves of secondary morphology are more common in this population [9].

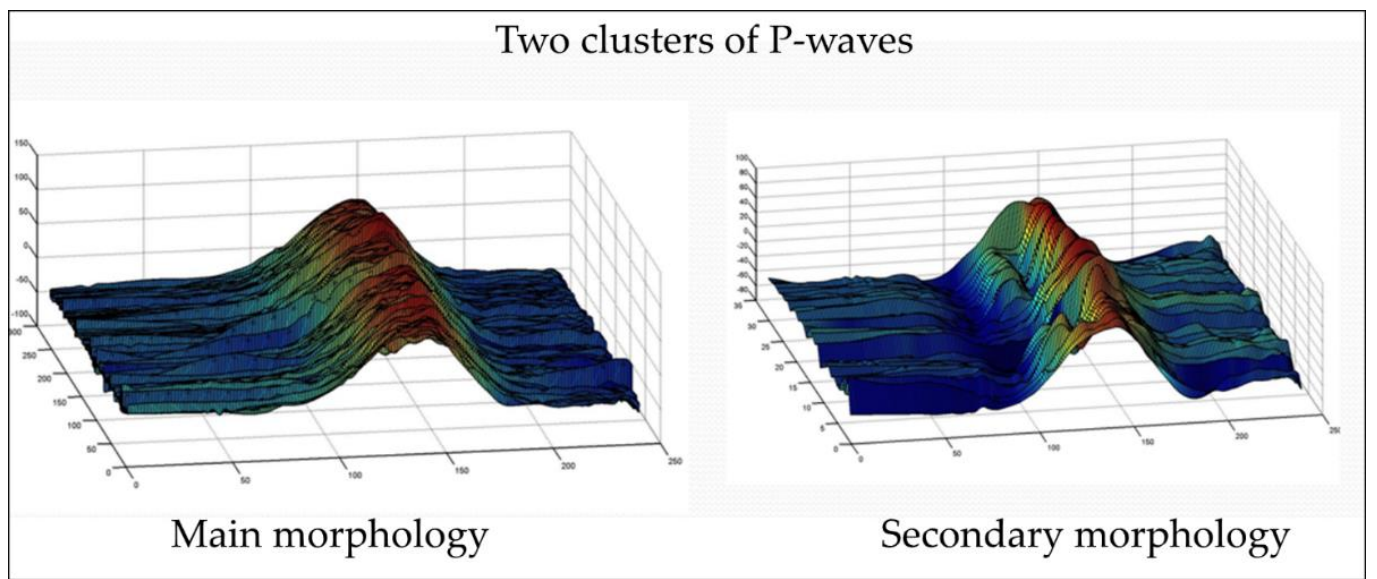

Figure A8. Beat-to-beat allocation of P-waves to main or secondary morphology.

Appendix A.2.2. Wavelet Analysis

P-waves of dominant morphology are analyzed on a beat-to-beat basis, and frequency features, such as mean or maximum energy, as well as time-frequency features, 
such as maximum energy location regarding P-wave onset, offset, or peak are calculated (Figure A9) [8,9].

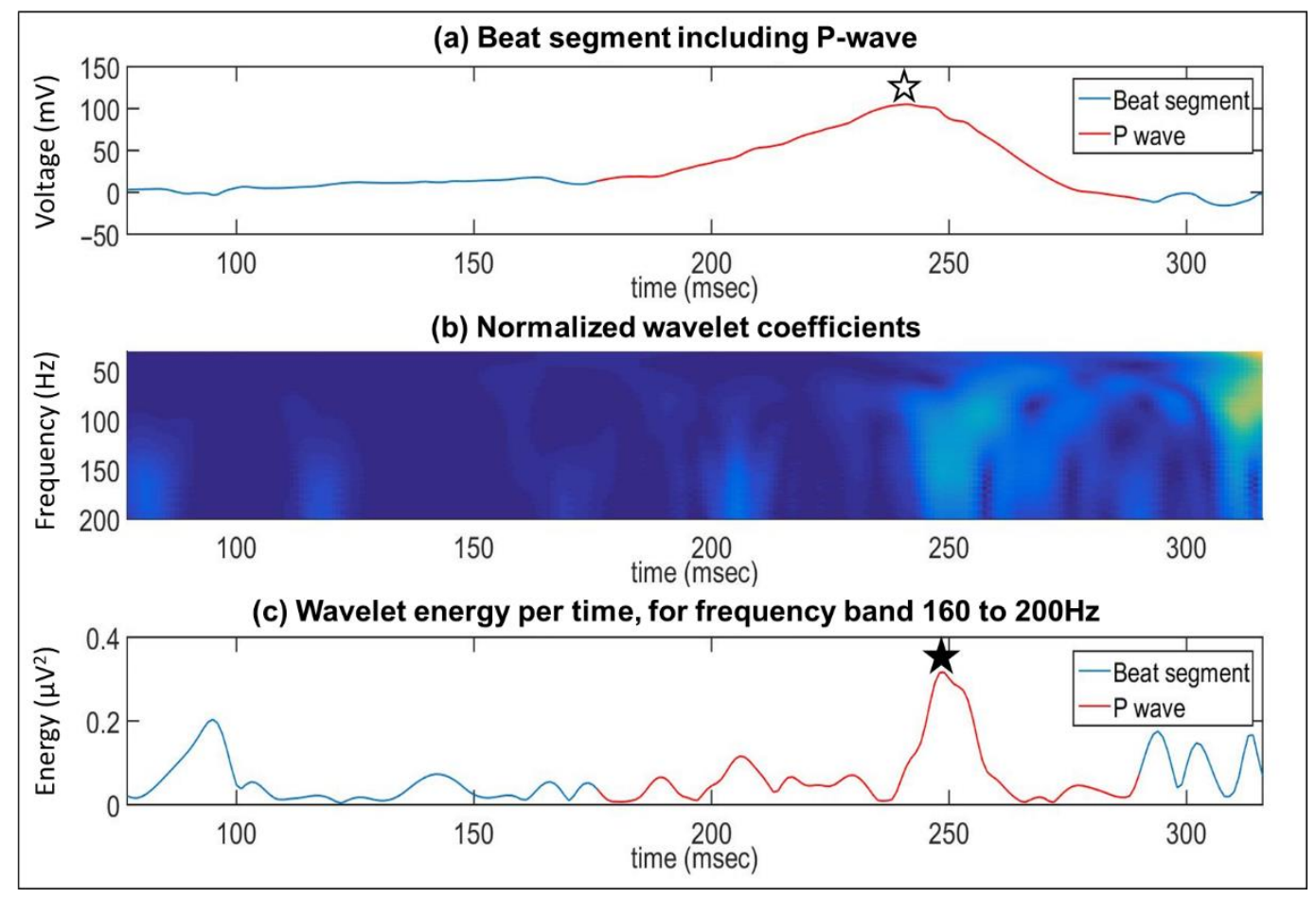

Figure A9. Example of wavelet analysis of an ECG signal: (a) ECG signal window of $250 \mathrm{~ms}$ preceding QRS complex. P-wave is depicted in red; (b) spectrogram of the same signal; (c) wavelet energy per time, for the high-frequency band. The white asterisk in panel (a) denotes the P-wave peak, while the black asterisk in panel (c) indicates maximum energy for this frequency zone.

\section{References}

1. Dilaveris, P.E.; Kennedy, H.L. Silent atrial fibrillation: Epidemiology, diagnosis, and clinical impact. Clin. Cardiol. 2017, 40, 413-418. [CrossRef]

2. Alonso, A.; Norby, F.L. Predicting Atrial Fibrillation and Its Complications. Circ. J. 2016, 80, 1061-1066. [CrossRef] [PubMed]

3. German, D.M.; Kabir, M.M.; Dewland, T.A.; Henrikson, C.A.; Tereshchenko, L. Atrial Fibrillation Predictors: Importance of the Electrocardiogram. Ann. Noninvasive Electrocardiol. 2016, 21, 20-29. [CrossRef]

4. Saliba, W.; Gronich, N.; Barnett-Griness, O.; Rennert, G. Usefulness of $\mathrm{CHADS}_{2}$ and $\mathrm{CHA}_{2} \mathrm{DS}_{2}$-VASc Scores in the Prediction of New-Onset Atrial Fibrillation: A Population-Based Study. Am. J. Med. 2016, 129, 843-849. [CrossRef]

5. He, J.; Tse, G.; Korantzopoulos, P.; Letsas, K.P.; Ali-Hasan-Al-Saegh, S.; Kamel, H.; Li, G.; Lip, G.Y.; Liu, T. P-Wave Indices and Risk of Ischemic Stroke. Stroke 2017, 48, 2066-2072. [CrossRef] [PubMed]

6. Martínez-Sellés, M.; Elosua, R.; Ibarrola, M.; De Andrés, M.; Díez-Villanueva, P.; Bayés-Genis, A.; Baranchuk, A.; Bayés-De-Luna, A. Advanced interatrial block and P-wave duration are associated with atrial fibrillation and stroke in older adults with heart disease: The BAYES registry. Europace 2020, 22, 1001-1008. [CrossRef] [PubMed]

7. Maheshwari, A.; Norby, F.; Roetker, N.S.; Soliman, E.Z.; Koene, R.J.; Rooney, M.R.; O’Neal, W.T.; Shah, A.M.; Claggett, B.L.; Solomon, S.D.; et al. Refining Prediction of Atrial Fibrillation-Related Stroke Using the $\mathrm{P}_{2}-\mathrm{CHA}_{2} \mathrm{DS}_{2}$-VASc Score: ARIC and MESA. Circulation 2019, 139, 180-191. [CrossRef]

8. Dakos, G.; Chatzizisis, Y.S.; Konstantinou, D.; Chouvarda, I.; Filos, D.; Paraskevaidis, S.; Mantziari, L.; Maglaveras, N.; Karvounis, H.; Styliadis, I.; et al. Wavelet-based analysis of $\mathrm{P}$ waves identifies patients with lone atrial fibrillation: A cross-sectional pilot study. Int. J. Cardiol. 2014, 174, 389-392. [CrossRef]

9. Filos, D.; Chouvarda, I.; Tachmatzidis, D.; Vassilikos, V.; Maglaveras, N. Beat-to-beat P-wave morphology as a predictor of paroxysmal atrial fibrillation. Comput. Methods Programs Biomed. 2017, 151, 111-121. [CrossRef] [PubMed]

10. Filos, D.; Tachmatzidis, D.; Maglaveras, N.; Vassilikos, V.; Chouvarda, I. Understanding the Beat-to-Beat Variations of P-Waves Morphologies in AF Patients During Sinus Rhythm: A Scoping Review of the Atrial Simulation Studies. Front. Physiol. 2019, 10, 742. [CrossRef]

11. Yıldırım, E.; Günay, N.; Bayam, E.; Keskin, M.; Ozturkeri, B.; Selcuk, M. Relationship between paroxysmal atrial fibrillation and a novel electrocardiographic parameter P wave peak time. J. Electrocardiol. 2019, 57, 81-86. [CrossRef] [PubMed] 
12. Huang, Z.; Zheng, Z.; Wu, B.; Tang, L.; Xie, X.; Dong, R.; Luo, Y.; Li, S.; Zhu, J.; Liu, J. Predictive value of P wave terminal force in lead V1 for atrial fibrillation: A meta-analysis. Ann. Noninvasive Electrocardiol. 2020, 25, e12739. [CrossRef] [PubMed]

13. Bayés de Luna, A.; Platonov, P.; Cosio, F.G.; Cygankiewicz, I.; Pastore, C.A.; Baranowski, R.; Bayés-Genis, A.; Guindo, J.; Viñolas, X.; Garcia-Niebla, J.; et al. Interatrial blocks. A separate entity from left atrial enlargement: A consensus report. J. Electrocardiol. 2012, 45, 445-451. [CrossRef] [PubMed]

14. Alexander, B.; Milden, J.; Hazim, B.; Haseeb, S.; Bayes-Genis, A.; Elosua, R.; Martínez-Sellés, M.; Yeung, C.; Ma, W.H.; Baranchuk, A.; et al. New electrocardiographic score for the prediction of atrial fibrillation: The MVP ECG risk score (morphology-voltage-Pwave duration). Ann. Noninvasive Electrocardiol. 2019, 24, e12669. [CrossRef] [PubMed]

15. Eranti, A.; Carlson, J.; Kenttä, T.; Holmqvist, F.; Holkeri, A.; Haukilahti, M.A.; Kerola, T.; Aro, A.L.; Rissanen, H.; Noponen, K.; et al. Orthogonal P-wave morphology, conventional P-wave indices, and the risk of atrial fibrillation in the general population using data from the Finnish Hospital Discharge Register. Europace 2020, 22, 1173-1181. [CrossRef]

16. Delong, E.R.; Delong, D.M.; Clarke-Pearson, D.L. Comparing the Areas under Two or More Correlated Receiver Operating Characteristic Curves: A Nonparametric Approach. Biometrics 1988, 44, 837-845. [CrossRef]

17. Peduzzi, P.; Concato, J.; Kemper, E.; Holford, T.R.; Feinstein, A.R. A simulation study of the number of events per variable in logistic regression analysis. J. Clin. Epidemiol. 1996, 49, 1373-1379. [CrossRef]

18. Magnani, J.W.; Zhu, L.; Lopez, F.; Pencina, M.J.; Agarwal, S.K.; Soliman, E.Z.; Benjamin, E.; Alonso, A. P-wave indices and atrial fibrillation: Cross-cohort assessments from the Framingham Heart Study (FHS) and Atherosclerosis Risk in Communities (ARIC) study. Am. Heart J. 2015, 169, 53-61.e1. [CrossRef]

19. Park, J.K.; Park, J.; Uhm, J.S.; Joung, B.; Lee, M.H.; Pak, H.N. Low P-Wave Amplitude (<0.1 MV) in Lead I Is Associated with Displaced Inter-Atrial Conduction and Clinical Recurrence of Paroxysmal Atrial Fibrillation after Radiofrequency Catheter Ablation. Europace 2016, 18, 384-391. [CrossRef]

20. Massó-van Roessel, A.; Escobar-Robledo, L.A.; Dégano, I.; Grau, M.; Sala, J.; Ramos, R.; Marrugat, J.; Bayés de Luna, A.; Elosua, R. Analysis of the Association Between Electrocardiographic P-Wave Characteristics and Atrial Fibrillation in the REGICOR Study. Rev. Esp. Cardiol. 2017, 70, 841-847. [CrossRef]

21. Conte, G.; Luca, A.; Yazdani, S.; Caputo, M.L.; Regoli, F.; Moccetti, T.; Kappenberger, L.; Vesin, J.-M.; Auricchio, A. Usefulness of P-Wave Duration and Morphologic Variability to Identify Patients Prone to Paroxysmal Atrial Fibrillation. Am. J. Cardiol. 2017, 119, 275-279. [CrossRef]

22. Censi, F.; Corazza, I.; Reggiani, E.; Calcagnini, G.; Mattei, E.; Triventi, M.; Boriani, G. P-wave Variability and Atrial Fibrillation. Sci. Rep. 2016, 6, 26799. [CrossRef]

23. Holmqvist, F.; Olesen, M.S.; Tveit, A.; Enger, S.; Tapanainen, J.; Jurkko, R.; Havmöller, R.; Haunsø, S.; Carlson, J.; Svendsen, J.H.; et al. Abnormal atrial activation in young patients with lone atrial fibrillation. Europace 2011, 13, 188-192. [CrossRef]

24. Engel, T.R.; Vallone, N.; Windle, J. Signal-averaged electrocardiograms in patients with atrial fibrillation or flutter. Am. Heart J. 1988, 115, 592-597. [CrossRef]

25. Okumura, Y.; Watanabe, I.; Ohkubo, K.; Ashino, S.; Kofune, M.; Hashimoto, K.; Shindo, A.; Sugimura, H.; Nakai, T.; Kasamaki, Y.; et al. Prediction of the Efficacy of Pulmonary Vein Isolation for the Treatment of Atrial Fibrillation by the Signal-Averaged P-Wave Duration. PACE_Pacing Clin. Electrophysiol. 2007, 30, 304-313. [CrossRef]

26. Savelieva, I.; Aytemir, K.; Hnatkova, K.; Camm, A.J.; Malik, M. Short-, mid-, and long-term reproducibility of the atrial signalaveraged electrocardiogram in healthy subjects: Comparison with the conventional ventricular signal-averaged electrocardiogram. PACE-Pacing Clin. Electrophysiol. 2000, 23, 122-127. [CrossRef] [PubMed]

27. Dhala, A.; Underwood, D.; Leman, R.; Madu, E.; Baugh, D.; Ozawa, Y.; Kasamaki, Y.; Xue, Q.; Reddy, S. Signal-Averaged P-Wave Analysis of Normal Controls and Patients with Paroxysmal Atrial Fibrillation: A Study in Gender Differences, Age Dependence, and Reproducibility. Clin. Cardiol. 2002, 25, 525-531. [CrossRef]

28. Aytemir, K.; Amasyali, B.; Abali, G.; Kose, S.; Kilic, A.; Onalan, O.; Tokgozoglu, L.; Kabakci, G.; Ozkutlu, H.; Nazli, N.; et al. The signal-averaged $\mathrm{P}$-wave duration is longer in hypertensive patients with history of paroxysmal atrial fibrillation as compared to those without. Int. J. Cardiol. 2005, 103, 37-40. [CrossRef] [PubMed]

29. Koide, Y.; Yotsukura, M.; Sakata, K.; Yoshino, H.; Ishikawa, K. Investigation of the predictors of transition to persistent atrial fibrillation in patients with paroxysmal atrial fibrillation. Clin. Cardiol. 2002, 25, 69-75. [CrossRef] [PubMed]

30. Budeus, M.; Felix, O.; Hennersdorf, M.; Wieneke, H.; Erbel, R.; Sack, S. Prediction of Conversion from Paroxysmal to Permanent Atrial Fibrillation. PACE-Pacing Clin. Electrophysiol. 2007, 30, 243-252. [CrossRef] [PubMed]

31. Platonov, P.; Mitrofanova, L.B.; Orshanskaya, V.; Ho, S.Y. Structural Abnormalities in Atrial Walls Are Associated With Presence and Persistency of Atrial Fibrillation But Not With Age. J. Am. Coll. Cardiol. 2011, 58, 2225-2232. [CrossRef]

32. Schreiber, T.; Kähler, N.; Tscholl, V.; Nagel, P.; Blaschke, F.; Landmesser, U.; Attanasio, P.; Huemer, M. Correlation of P-wave properties with the size of left atrial low voltage areas in patients with atrial fibrillation. J. Electrocardiol. 2019, 56, 38-42. [CrossRef] [PubMed]

33. Nagel, C.; Luongo, G.; Azzolin, L.; Schuler, S.; Dössel, O.; Loewe, A. Non-Invasive and Quantitative Estimation of Left Atrial Fibrosis Based on P Waves of the 12-Lead ECG-A Large-Scale Computational Study Covering Anatomical Variability. J. Clin. Med. 2021, 10, 1797. [CrossRef] [PubMed] 
34. Filos, D.; Korosoglou, P.; Tachmatzidis, D.; Maglaveras, N.; Vassilikos, V.; Chouvarda, I. Multiple P-Wave Morphologies in Paroxysmal Atrial Fibrillation Patients During Sinus Rhythm: A Simulation Study. In Proceedings of the 2018 Computing in Cardiology Conference (Cinc), Maastricht, The Netherlands, 23-26 September 2018; IEEE Computer Society: Maastricht, The Netherlands, 2018; pp. 1-4.

35. Pezzuto, S.; Gharaviri, A.; Schotten, U.; Potse, M.; Conte, G.; Caputo, M.L.; Regoli, F.; Krause, R.; Auricchio, A. Beat-to-beat P-wave morphological variability in patients with paroxysmal atrial fibrillation: Anin silicostudy. Europace 2018, 20, iii26-iii35. [CrossRef] [PubMed] 